\title{
EXPERIMENTOS GRÁFICOS
}

Alecrim

A Alecrim é um projeto editorial que se pauta pela edição como gesto poético e criativo. Dentro disso, trabalhamos com projetos de publicação de forma colaborativa e experimental, buscando tensionar as fronteiras entre a autopublicação, o livro-objeto e o livro de artista.

Desenvolvemos, em parceria com a Lume7 - Espaço de Arte, os colaboratórios gráficos: encontros para imersão, experimentação e acompanhamento de processos artesanais do livro.

Outro projeto em andamento é o caderno de traduções. Postamos, sempre que possível, traduções de poemas ou textos de autores que de algum modo dialogam ou influenciam o nosso trabalho. Pretendemos, em algum momento, publicar uma versão impressa com essas traduções.

Publicamos também entrevistas com editores, poetas e artistas que também se apropriam do fazer editorial como um fazer poético.

https://alekrym.wordpress.com/

https://www.facebook.com/alekrym 


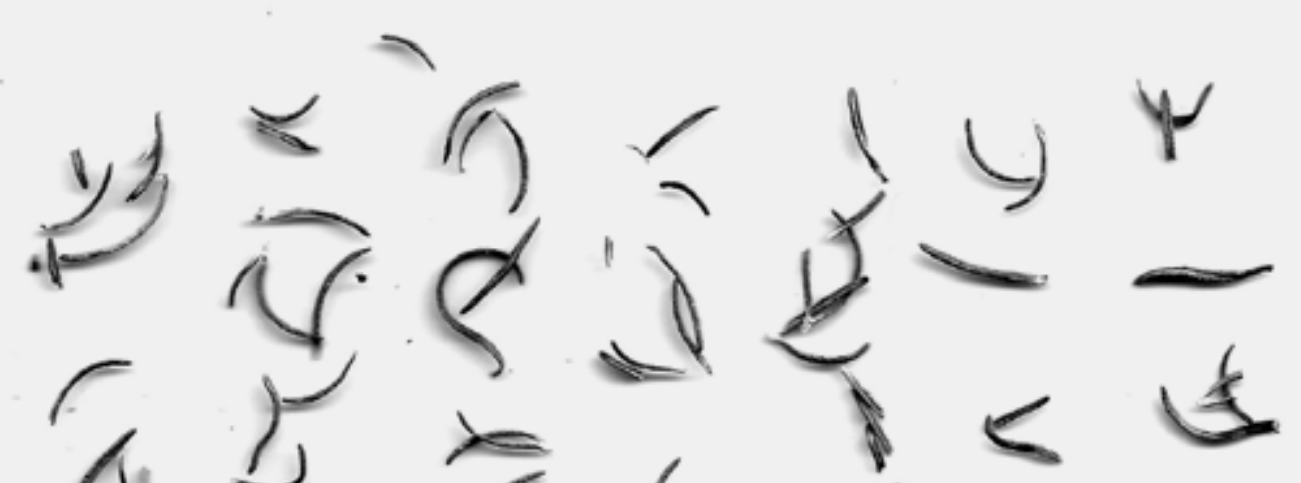

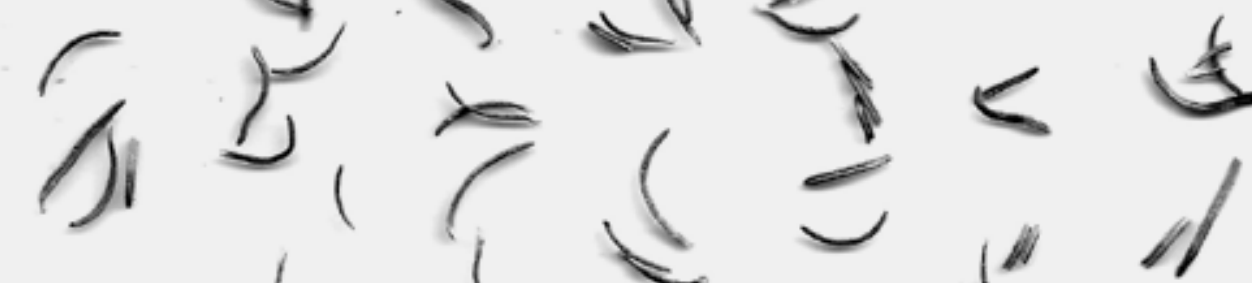

$$
\begin{aligned}
& \text { 저의 }
\end{aligned}
$$

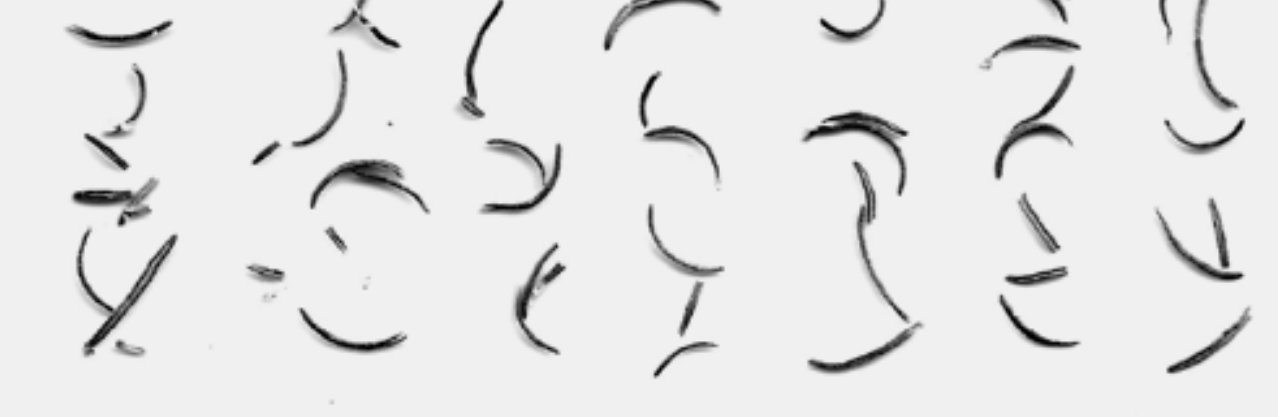




$$
\begin{aligned}
& \text {. }
\end{aligned}
$$






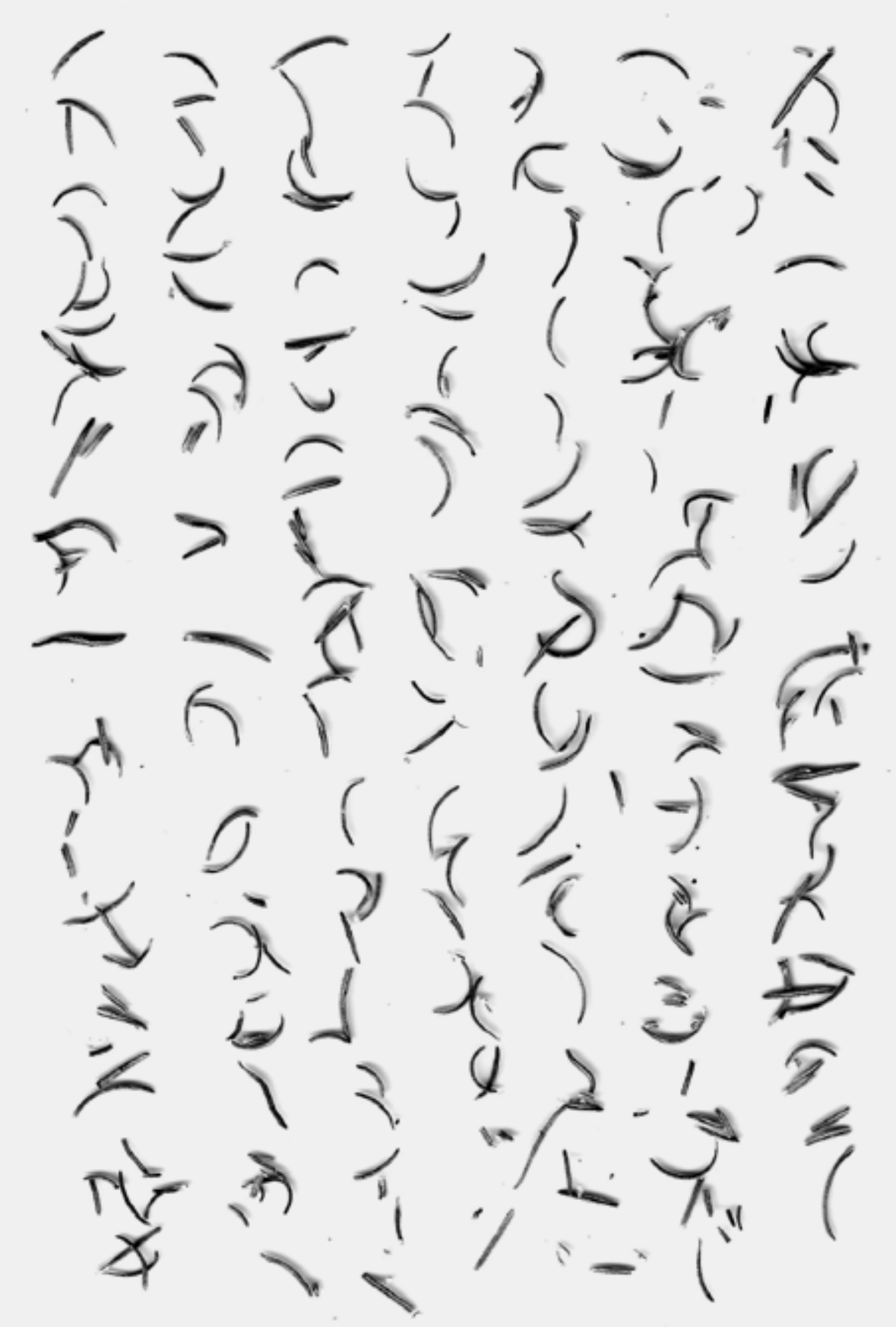




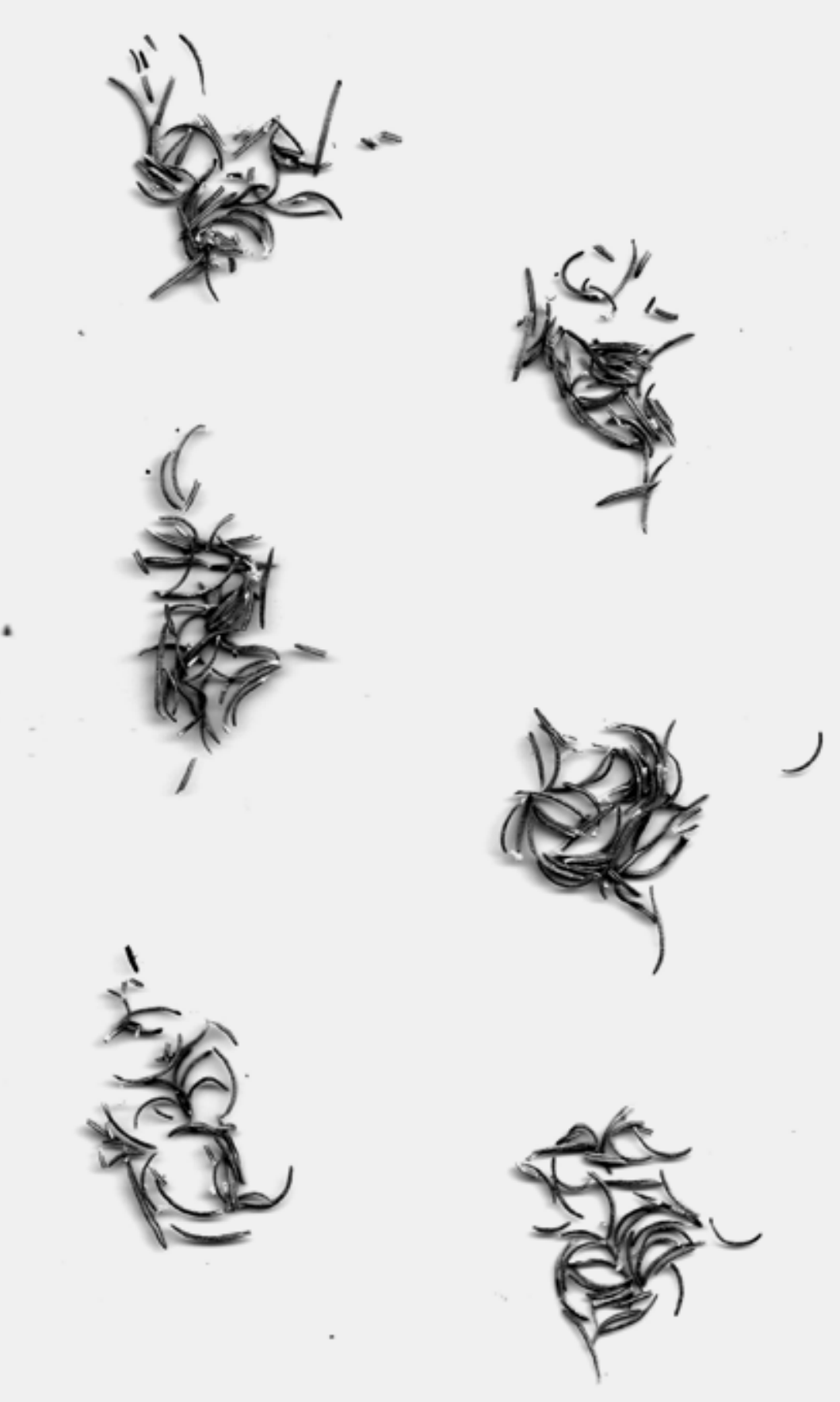




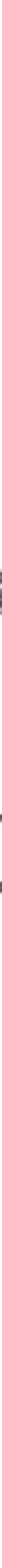



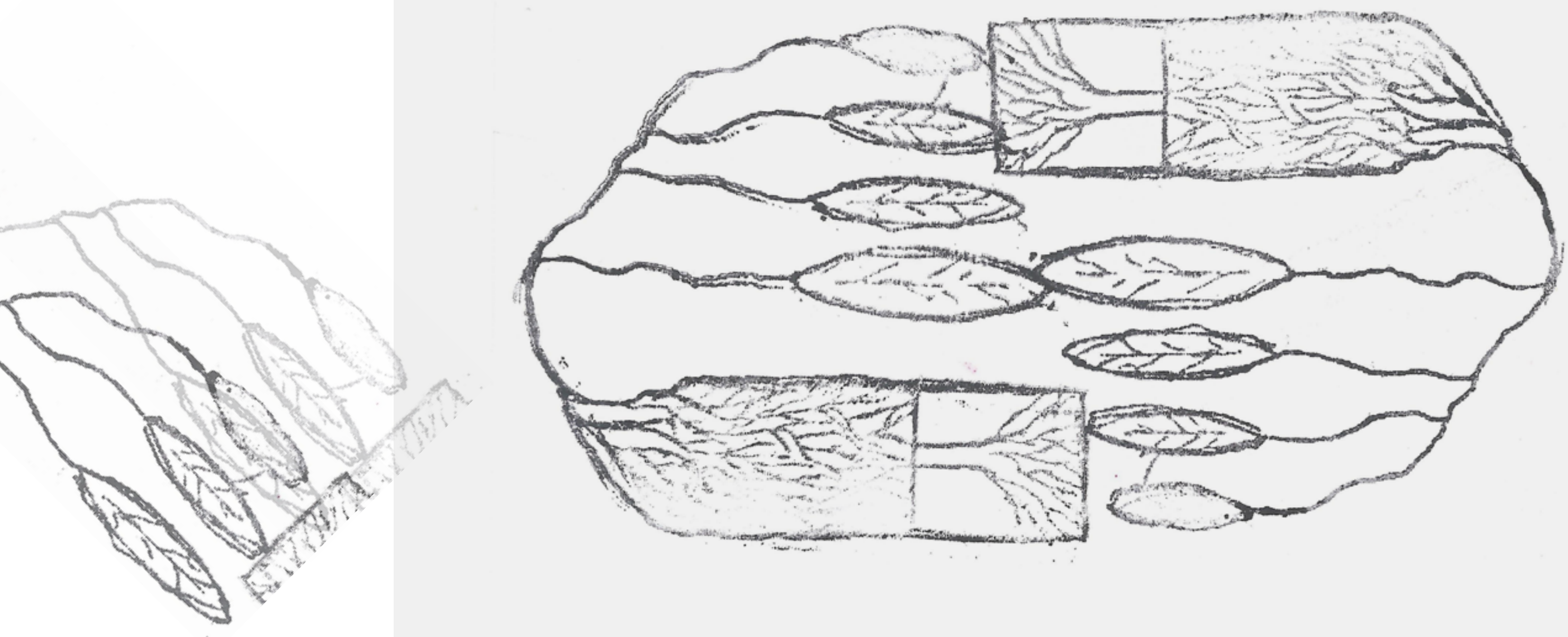


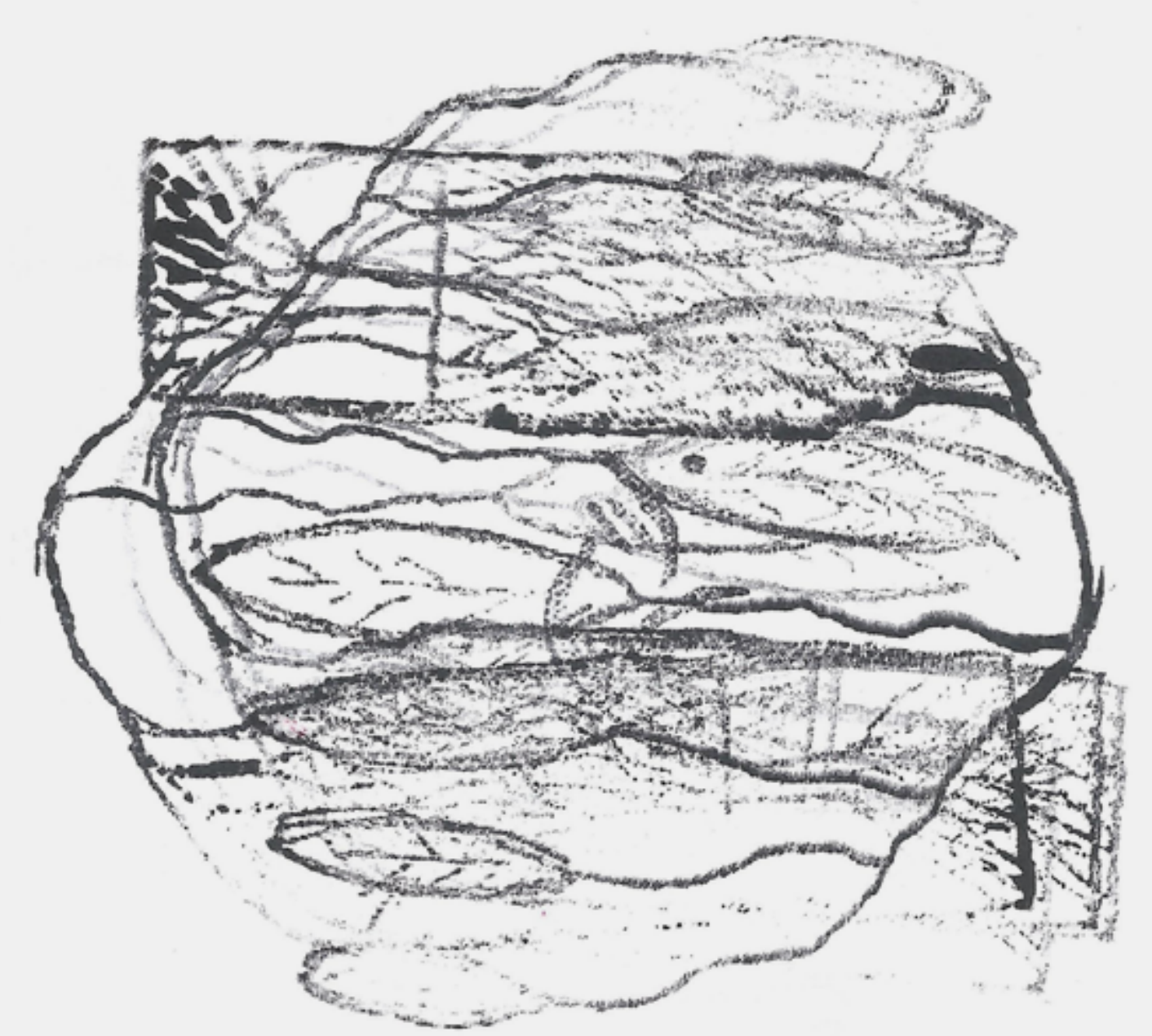

EM TESE 




